\title{
6. (Un)realized agency in a situation of early job insecurity: patterns of young people's agency regarding employment
}

\section{Pepka Boyadjieva and Petya Ilieva-Trichkova}

\section{INTRODUCTION}

Researchers have been giving greater attention recently to the different factors underlying the problems and challenges young people face in integrating into the labour market (e.g., Chung and Van Oorschot, 2010; Eurofound, 2014). Several studies have explored the institutional determinants of early job insecurity in European countries (Hora et al., 2016) and the risk factors for young people's careers in Europe during the economic crisis (Karamessini et al., 2016). However, existing research has less to say about how young people use their scope for agency within the institutional constraints they experience. This chapter focuses on the ways in which young people convert available resources into desired ways of living and flourishing ('functionings') in key social areas, such as education, employment, family formation, civic participation and cultural activities. Amongst these areas, the sphere of employment is particularly important for individuals' well-being. We address the following research questions:

1. What are the patterns of active agency regarding employment of young people experiencing early job insecurity?

2. Which factors have hindered the agency regarding employment of young people experiencing early job insecurity?

3. Do the patterns of active agency of young people differ by national context and/or employment regimes?

The chapter proceeds as follows. First, we outline the theoretical considerations behind the framework of the analysis. Next, we present the data and our main findings. We then proceed with a discussion of the identified 
patterns of active agency with respect to the first stable job in a countrycomparative perspective. Our concluding remarks summarize the main contributions of the chapter and suggest directions for further research.

\section{THEORETICAL CONSIDERATIONS}

This chapter draws on the capability approach (Nussbaum, 2011; Sen, 1999, 2009) and its main concepts, as presented by Hvinden et al. (Chapter 1 this volume). Numerous studies have explored (un)employment and employability from the perspective of the capability approach (e.g., Hinchliffe and Jolly, 2011; Hollywood et al., 2012; McQuaid and Lindsay, 2005; Olejniczak, 2012; Otto, 2015). Most of these studies focus on young people or other vulnerable groups on the labour market, rejecting the reduction of human beings to their employability and human capital (e.g., Bonvin and Farvaque, 2006; Otto, 2012; Schneider and Otto, 2009). Notwithstanding this large body of literature on youth employment, few publications have discussed the issue of agency in any detail (see Bonvin and Farvaque, 2006; Egdell and Graham, 2017). We find hardly any systematic consideration of the different forms of agency that people may adopt to overcome early job insecurity.

\subsection{Agency and Conversion Factors}

The capability approach provides useful ideas for conceptualizing the (un) realized agency of disadvantaged groups; for instance, that of young people experiencing early job insecurity. This approach considers all individuals as active agents (Alkire, 2009). The concept of agency implies that all people enjoy a certain space of freedom within which they can make choices and act accordingly. Agency takes account of the active role that people may have in shaping their own destinies and the societies in which they live. The agent 'is someone who acts and brings about change, and whose achievements can be judged in terms of her own values and objectives, whether or not we assess them in terms of some external criteria as well' (Sen, 1999: 19). This definition relates to the ability to pursue and realize ways of living or flourishing that one values and has reason to value (Alkire and Deneulin, 2009: 31, 37). We can distinguish between two aspects of agency: freedom and achievement. Whereas 'agency freedom' is related to the 'freedom to bring about the achievements one values and which one attempts to produce' (Sen, 1992: 57), the 'achievement' of a person's agency 'refers to the realization of goals and values she has reason to pursue, whether or not they are connected with her own well-being' (Sen, 1992: 56).

In paying attention to agency freedom and agency achievements, 
the capability approach shifts the focus away from seeing a person as just a vehicle of well-being and towards stressing the importance of the person's own judgements and priorities, with which the agency concerns are linked (Sen, 2009: 288). Such an understanding of agency emphasizes people's active role and their capacity to change and transform reality in accordance with their conception of the good, once this conception has passed reasoned scrutiny. We consider agency as a constitutive element of social resilience, where the latter is related at individual level to the '[o] pportunity to acquire a feeling of well-being, ability to cope with adverse circumstances and realize valued and meaningful achievements in the short and long term' (see Hvinden et al., Chapter 1 this volume).

Agency concerns the active role of people in all spheres of life, including work. Thus, a person may act to mitigate early job insecurity and to influence his/her job prospects, in general, or to negotiate working conditions, in particular. However, although the capability approach to agency implies a certain measure of individual responsibility, it does not involve the trap of blaming the victim because it acknowledges human diversity and the wide range of factors that enhance, or constrain, a person's ability to exercise his/her agency in practice/reality. This implies that different people have different capacities to transform their resources into real agency or outcomes.

In order to understand people's agency, we need to know more about the context and structures in which they are embedded (Granovetter, 1985). In this regard we rely on the heuristic potential of the concept of conversion factors. These are defined as a range of factors that influence how a person can convert the characteristics of his/her available resources (initial conditions) into freedom or achievement. Different authors propose different classifications of conversion factors (Crocker and Robeyns, 2009; Robeyns, 2005; Sen, 1999: 70-71). Here we classify the relevant conversion factors according to the level at which they operate: micro, meso or macro (see Hvinden and Halvorsen, 2017; Hvinden et al., Chapter 1 this volume). In taking conversion factors into account, the capability approach enables consideration not only of the role of individual-level characteristics in the evaluation of inequalities, but also of how interactions between the individual, intermediate and institutional levels affect these inequalities.

\subsection{Conceptual Model of a Person's (Un)Realized Agency}

Based on this review of analytical concepts, we define agency as the mediating processes (interactions with others) whereby young people may convert available resources into new prospects for strengthening their capability for work and for enlarging their scope for real choice with 
regard to employment. Each mediating process might broaden or narrow young people's achieved functionings. In other words, conversion factors can be either constraining or enhancing of people's effective freedom (Hvinden and Halvorsen, 2017: 6). The actual agency achievements of young people may also reflect differences in their goals and the particular things they value. In all cases, however, for an actor to transform a capability set into agency achievement, an act of choice is necessary.

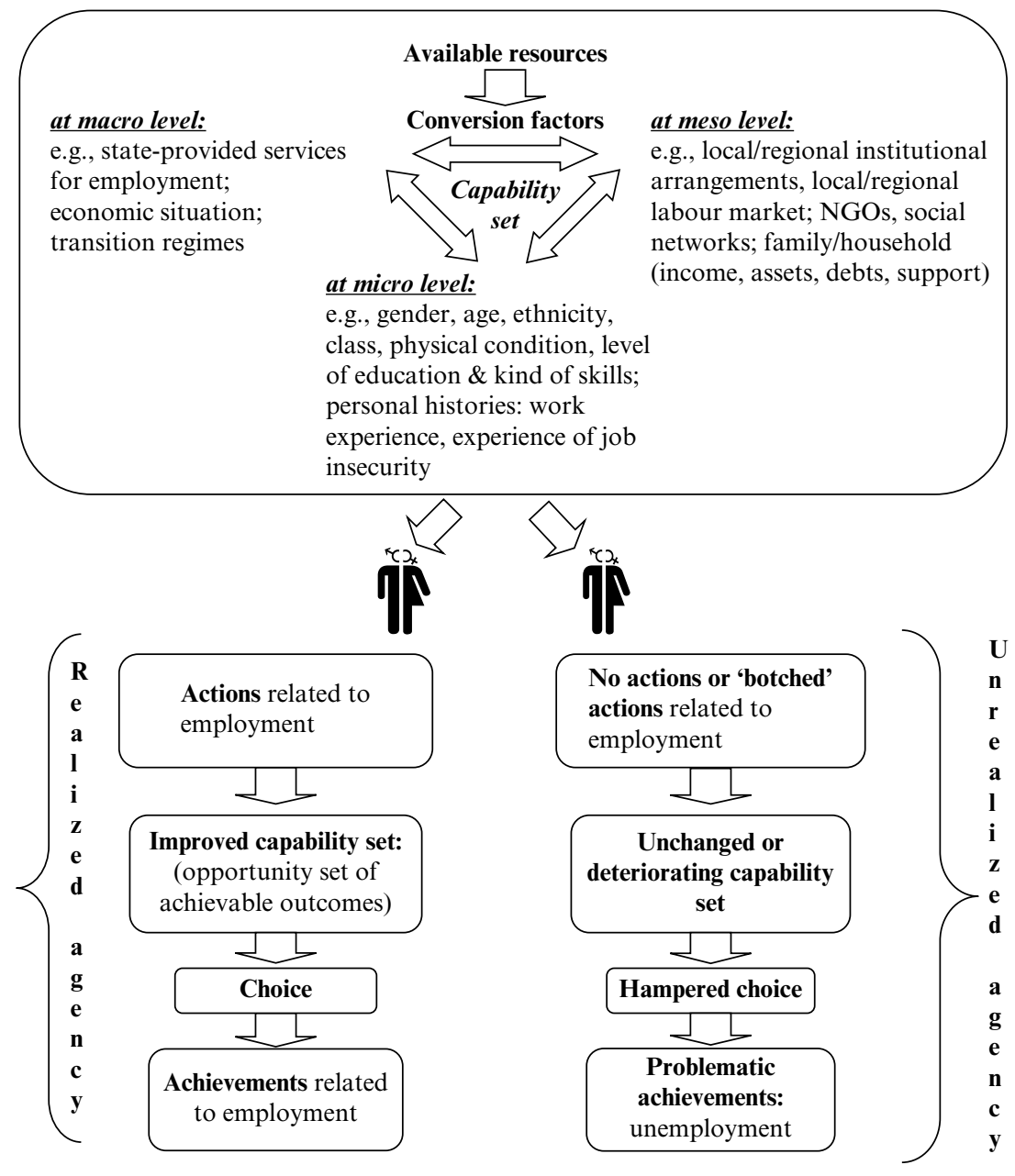

Source: Own illustration.

Figure 6.1 A static representation of a person's (un) realized agency 
Figure 6.1 presents in a more systematic way our theoretical understanding of (un)realized agency.

\section{RESEARCH STRATEGY AND EMPIRICAL BASE}

Given the importance of conversion factors and their role in mediating the scope of agency of young people experiencing early job insecurity, as well as the varying extents to which young people manage to convert their available resources into agency achievements, we use two main criteria for identifying different patterns of young people's agency:

1. What were the essential interactions with others (institutions and individuals) whereby young people were able to exercise agency in a situation of early job insecurity?

2. Did young people succeed in converting their resources into agency achievements related to employment and, if so, how?

We base the analysis on data from 81 semi-structured life-course interviews with women and men belonging to the birth cohort 1990-95 in seven EU countries: Bulgaria (BG), the Czech Republic (CZ), Germany (GER), Greece (GR), Norway (NO), Poland (PL) and the United Kingdom (UK). All interviewees had experienced unemployment or job insecurity by the time they were 25 years of age. Each national team of researchers first produced a transcript of each interview in their national language and a synopsis with quotations in English and then prepared a national summary. Hvinden et al. (Chapter 1 in Volume 2) and Tolgensbakk et al. (2017) describe the methodology. To respect the anonymity of the interviewees, we refer to them using pseudonyms, indicating their country and gender; for instance, 'Tatiana (BG Female)'.

We carried out a three-step analysis of the interviews. In the first step we each independently read the extended summaries of the life-course interviews with the aim of identifying the mediating processes through which young people had tried to convert available resources into new prospects and scope for choice with regard to employment. We did not consider how common each of the mediating processes was, rather only whether it represented a different type of interaction with institutions and individuals. In the second step we compared the interactions with others (institutions and individuals), as identified by each of us researchers. There was about 90 per cent coincidence in the identified interactions. We then selected and classified common interactions with others, introducing the notion of patterns of agency to capture the different mediating processes through which 
young people converted available resources into new prospects related to employment. Thus, we identified different patterns within the two broad groupings of agency: realized agency (patterns of accomplished interactions with institutions and individuals) and unrealized agency (patterns of not accomplished interactions with institutions and individuals).

In the third step we each independently classified the life-course interviews based on these two patterns of agency. The few cases about which we disagreed we classified as 'unclear'. Given that young people might have followed different trajectories each time they sought employment, we focused only on the patterns of agency adopted with regard to their first stable job (contracted full-time employment for at least six months). In some cases we relied on the interviewees' subjective assessment of what constituted a stable job. For cases where the interviewee never had such employment, we focused on the first part-time job or temporary job.

\section{RESULTS}

\subsection{Patterns of Exercising Agency Regarding Employment}

We found several patterns of agency in relation to employment amongst young people who had experienced early job insecurity. More specifically, within the two groups of patterns - of realized and of unrealized agency we identified the following different sub-patterns:

Realized agency: patterns of implemented interactions with institutions and individuals

- Self-relying agency;

- Self-improving agency;

- Institutionally enabled agency by: (a) state institutions; (b) nongovernmental organizations (NGOs);

- Informally enabled agency by: (a) family and relatives; (b) friends and networks; and

- Agency enabled by social commitment.

Unrealized agency: patterns of not implemented interactions with institutions and individuals

- Disoriented and unmotivated agency;

- Hampered agency at: (a) micro level by personal characteristics and problems; (b) meso level by inadequate career and employment 
services; (c) macro level by national policies and societal problems; and

- Blocked agency.

We see the identified patterns as ideal types in the Weberian sense (Engerman, 2000: 258). They are heuristic devices for analysis and do not represent the most common modes of action of young people in the countries studied. The patterns focus on the essential social interactions through which agency was realized (or not) in a situation of early job insecurity. We have constructed them based on key elements of the life courses of our interviewees but we did not find these constructions fully in any of our interview cases. It is also important to emphasize that we are studying agency in relation to employment and within a longer time span of young people's life courses.

\subsection{Description and Empirical Manifestation of the Identified Patterns of (Un)Realized Agency}

Below we provide a short description of the identified patterns and use these as analytical instruments to describe and understand the scope of agency of young people in the situation of early job insecurity.

\section{Patterns of realized agency}

Self-relying agency: This pattern refers to young people who in a situation of early job insecurity managed to convert their resources by undertaking different actions, relying mainly on themselves and not on support from state institutions or informal networks. They succeeded in broadening their capability set and, as a result, in achieving improved prospects for employment:

After several failed attempts at finding a job, Ania (PL Female) decided to behave more proactively. She says: 'Fortunately, after that time, I decided not to wait for job offers from the District Employment Office. I decided to look for work on my own and I succeeded. I used to send e-mails to lots of companies and public institutions. That's how I managed to get an internship at the Customs Chamber in Lodz.'

Self-improving agency: This pattern refers to young people who, after being in a situation of early job insecurity, decided to improve their knowledge and skills mainly through education. By broadening their capability set, they expanded their scope for real choice with regard to employment.

Depression led to psychiatric care and Marit (NO Female) moved to a small village to live in a residential unit for young people (i.e., a care facility for young 
people who could not live at home because, e.g., of parental neglect or abuse). The unit placed her in a job against her will. On her own she then managed to finish upper-secondary school and obtain a BA university degree. She is currently enrolled in another programme at a university college. Volunteer work has been very important to the interviewee.

Institutionally enabled agency: This pattern refers to young people who managed to transform their situation by undertaking different actions with the decisive support of different institutions, such as state employment agencies and NGOs. They succeeded in negotiating institutional support and in benefitting from it. Thus, they were able to broaden their capability set and, consequently, achieve improved prospects in relation to employment.

(a) Agency through state institutions: The state employment agencies and labour offices were the main state institutions that were legally obliged to support young people during unemployment by guaranteeing them different benefits (unemployment benefits, maternity and childcare allowances, health and social insurance, social assistance) and also by providing information and guidance and offering training and jobs. The institutional support coming from the state institutions broadened some young people's scope for agency in two ways: by helping them to cope with financial problems during unemployment and by providing them with various choices for action related to training and employment.

Stavros's (GR Male) parents could not help him find a new job after the closure of the family business. He searched alone through newspaper advertisements and also turned to the Public Employment Agency (OAED). He has a very good opinion of the OAED because he found his present job through them: 'They helped me a lot to find what I was looking for [OAED]. The lady was very helpful. She made a huge effort. She kept looking for new positions for me and offered me many jobs.'

(b) Agency through NGOs: In taking part in activities and programmes organized by NGOs, some young people in a situation of early job insecurity managed to broaden their capability set not only by acquiring new knowledge and experience but also by changing their values, goals and life orientations. Through interactions with NGOs some young people became involved in meaningful and socially sensitive activities and built a capacity for agency that is not only self-regarding but also other-regarding.

Albert (CZ Male) left home without finishing secondary school because of a family and personal crisis. He spent about four years not looking for work, ending up in debt. He did not register at the Employment Office and did not receive any financial or other support. An NGO provided him with a temporary 
job and helped him to plan paying off his debts. He identifies highly with this NGO and is committed to the work he is doing (work with mostly Roma children and youngsters and their families). The agency he achieved improved the young man's self-confidence and aspirations - he now plans to go on to upper-secondary education and then to university.

Informally enabled agency: In a situation of early job insecurity, interactions with informal contacts - family, relatives, friends and social networks - were very important mechanisms through which some young people sought to overcome difficult situations (both material/financial and psychological) and to convert their available resources into new prospects regarding employment. This pattern built on informal, intimate and highly emotional interactions. Thus, when they had reliable and strong connections with informal circles, some young people could rely on these several times over and in different situations. This broadened these young people's scope for agency and provided a safety net that protected them from the negative consequences of early job insecurity. Conversely, young people who had broken off relations with their families and friends risked 'falling into a vacuum' or giving up when interactions with official institutions turned out to be ineffective or counterproductive.

(a) Agency enabled by family and relatives: Some young people's families and relatives were able to broaden their scope for agency in various ways: by ensuring them a livelihood and thus freeing them from the burden of 'surviving without any money' (offering a home free of charge and giving financial support), by providing emotional support and advice, and by seeking and finding job and training offers. Thus, for these youths, the family turned out to be the main safety net and a main source of social resilience. In periods of early job insecurity, or when they lacked financial resources, many young people postponed leaving their family home.

Elena (PL Female) after graduating from high school was looking for a job in her hometown. The encounter with the labour market was hard for her. She realized that she did not have the skills that would make employers want to hire her. . .Her sister helped her to find work: 'At the moment the biggest support is my sister, who had a very similar experience on the job market. . . She was such an inspiration for me, and I followed her example.'

(b) Agency enabled by social networks and friends: Young people's social capital - their social networks - was an important factor that could influence their scope of agency positively and in various ways in a situation of early job insecurity, including by motivating them to act, by orienting their actions and by supporting them both financially and emotionally during their efforts. The wider and more diverse the social network of a 
young person, the more likely it was that it might enlarge his/her scope for action and opportunities for choice in finding a job (Granovetter, 1973). However, while social networks might lead to socially relevant and personality-developing actions, they might also lead to involvement in unsocial and risky behaviour.

Yianna (GR Female) had found almost all her jobs through contacts: 'As I told you before, my social network offered me a job without me even saying anything. For example, I found my first job from a family friend. We were discussing that I was looking for a job. He knew someone who was looking for an employee and he thought of me. After that, I found my next job from a newspaper [advertisement]. The third was again through a recommendation by a contact of mine.'

Agency enabled by social commitment - volunteering: This pattern refers to young people who enhanced their capability set by engaging as volunteers in causes and activities. As a process of involvement in work and activities without pay (which differentiates it from all other patterns of agency), volunteering might be a transformative and empowering experience. By definition, it is impossible to force people to volunteer - they became volunteers of their own free will and were committed only to activities they viewed as meaningful. Volunteering empowered people by increasing their experience, knowledge, confidence and social capital. However, initially it may have been considered 'just a place to be' (Stig, NO Male) or a way 'to come out of my shell' (Josh, UK Male).

Jesse (UK Male) lost a job at age 19. He suffered from depression, mood swings and fatigue and was diagnosed and medicated for a chemical imbalance. He was smoking marijuana heavily and was in and out of about 10 casual jobs. None of his jobs lasted for more than three months. A life-changing experience for Jesse was his work as a volunteer in a HIV-testing clinic abroad: 'I can't remember a day out there that I didn't start crying at some point. It was really quite shocking.' This experience transformed his beliefs and changed him completely.

To sum up, the analysis of the semi-structured life-course interviews showed that each of the patterns of realized agency led to and involved different actions. We identified the following actions:

- Getting in contact with the state employment agency;

- Looking for advertisements through different channels;

- Setting up a business of one's own;

- Approaching employers directly or sending them CVs and applications; 
- Filing complaints if an employer did not comply with the law;

- Migrating within the same country or abroad;

- Looking for a job in the shadow economy;

- Engaging in voluntary work;

- Looking for an apprenticeship, etc.

As regards agency achievements, examples included the following:

- Accepting a part-time job or accepting a job without a contract;

- Getting a stable job that corresponded to one's level of education or to one's field of education, or accepting a job that did not match one's qualifications; and

- Succeeding in finding a meaningful job.

We emphasize that we did not find a one-to-one link between the actions and agency achievements; that is, each of the actions could lead to any one of the identified agency achievements.

The examples of agency achievements involved an improvement in one's employment situation compared to being in a situation of early job insecurity. In most cases, the person might potentially improve his or her achievements.

\section{Patterns of unrealized agency}

These patterns referred to the experience of young people who were not able to convert their resources into improved employment prospects. Their scope of action was very limited either because they did not have clear goals or because of other constraints outside of their control. Thus, their attempts to take action were constrained, and even when they undertook some actions, these appeared to be somehow disoriented, neither contributing to broadening the person's capability set nor improving his/ her employment situation.

Disoriented and unmotivated agency: The main characteristic of this pattern of agency was that the young person seemed to be unable to formulate clear goals that he or she would like to pursue. This pattern appeared to be prevalent amongst young people who had experienced early job insecurity. For instance, some of the interviewees did not really have any firm idea what they wanted to do after school, or they had unrealistic ideas about their futures, such as becoming an actor or a fashion model. Many young people broke off their vocational training or cancelled their employment contract after completing vocational training because they realized that this was not the right path for them. Many had unclear visions of their future. In many cases they lacked information about the real conditions 
in the professions they chose and their attitude towards the prospective job already changed during their studies. Overall, the actions that these young people undertook were few and they lacked clear direction. In these cases the young people mostly suffered from a lack of (career) advice to make their goals clearer or more realistic and to help them envisage new ambitions.

After his graduation (upper-secondary school) Eric (GER Male) moved to another city, with the motivation just of being somewhere else. There he had a marginal involvement in the retail trade, only as an unskilled worker. After one year he moved to Hamburg and tried to find another marginal job. Eric described very extensive professional disorientation. He continued not to know what professional goals he should pursue and what training would be suitable for him.

Hampered agency: The main characteristic of this type of agency is that it is limited by different factors:

(a) Agency hampered by personal characteristics and problems: In this case, agency was limited because of scarring and discrimination effects associated with young people's characteristics, such as having children, age, or lacking working experience or relevant education. The scarring effect was so strong that it constrained the person's scope for action or the person did not have sufficient capacity to deal with it.

However, agency might also be hampered by personal problems and family troubles. Thus, some of the interviewees did not find a job after school because of early (single) motherhood, use of drugs, truancy, constant conflicts with superiors, juvenile delinquency or involvement in youth gangs and so forth. Although many young people found support and stimulus for action in their families, for some of them families represented a constraint and undermined their scope of agency. Typical cases were that parents were unemployed, there were conflicts between parents and children, parents divorced or parents forced their children into professions that the children disliked.

Claudia (GER Female) left school at age 16 with no qualifications. Until then she had not thought about her future. After a conflict with her mother, Claudia was placed in a youth facility (i.e., a special institution where youth under 18 can live in supervised residential communities). In this youth facility she developed delinquent behaviour. She then had to move to a facility in another town. There she carried out an internship at a bakery. At age 18 she returned to her home town. She lived from day to day without thinking about her future and without making any plans, drawing unemployment benefit II (ALG II). Because of her lack of educational attainment, she regarded any effort to apply for vocational training as unrealistic. 
(b) Agency hampered by inadequate career and employment services: In several cases, the capacity of state institutions to empower young people to act and to broaden their capability set turned out to be problematic. Many young people assessed the institutional support provided by the employment offices as meagre, unsuitable, not topical or even counterproductive. In particular, they tended to see job counselling and remedial classes as unhelpful and ineffective, and they assessed the jobs offered as not providing sustainability:

In general, it [state] does not help young people. . .because, for instance, they hire them for six months or less. (Galina, BG Female)

Some young people experienced discrimination at the workplace (based on age, motherhood, ethnicity, disability or lack of experience). The difficulty of getting suitable qualifications and jobs from the employment office obliged young people to organize the desired education programmes by themselves or to turn to their family members and social networks for support. Thus, it became clear that young people who experienced the ineffectiveness of one source for converting their available resources into new life prospects might start looking for another source of support.

There was no mention of advice at school and Josh (UK Male) was negative about the support provided by the Job Centre, which mostly consisted in referral to websites. Josh said: 'It is just hard to find someone that will actually help you. . .they told me what to do and then left me to it. It was very hard to find a job after that.' Josh repeated several times that he felt unsupported in trying to improve his employability. His message to government was 'just give a bit more effort in helping people'.

(c) Agency hampered by national policies and societal problems: Finally, yet importantly, factors at macro-level related to national labour market and migration policies, restructuring of economic sectors, or economic downturns can hamper agency:

I mean, the financial crisis destroyed us, I mean, I can't find work since 2008 and there are no jobs. Before it was much better. . each season I worked as a lumberjack. I told you, I could make 1,000, 1,500 leva for the season. And 1,500 leva was good money, enough to make a living, but today I hardly make 700 leva. After 2008 everything was cut short and life has become much more expensive. (Emil, BG Male)

Blocked agency: Blocked agency refers to a situation of unemployment that absolutely 'paralysed' and dispirited the young person. The interviewee had fallen into a prolonged period of despair and depression 
and was unable to undertake any actions to improve his/her situation. These young people felt helpless and unable to overcome the situation of early job insecurity, and every failure to do so further demotivated them. A hurdle arose at every step of their actions in their efforts to achieve their goal. This pattern often went hand in hand with deteriorated mental wellbeing or health problems. Thus, most of these people suffered from a lack of psychological/medical support.

After leaving education Bogdan (BG Male) lived in a protected dwelling for children without parents. It was difficult for him to find a job: 'It is simply hard for me, I feel a bit embarrassed when I go to job interviews.' His first job, which lasted only four days, was as a restaurant dishwasher. This inability of the respondent to keep a job is typical for him: 'When I find a job, I don't know, I don't know how to stick to it for long. ... He wanted to continue his education, but he had a diploma only for the eighth grade because of what had happened to his tenth-grade diploma: 'I did a naughty thing and I burned it without meaning to.' The reason for this behaviour was that the diploma had not helped him get a job: 'I set my diploma on fire because I got irritated that they would not give me a job anywhere with it.'

In ending this section we would like to emphasize that in many of the cases studied, two or more interactions co-existed and produced combined patterns. Thus, some young people in a situation of early job insecurity benefited from both volunteering (agency enabled by social commitment) and state or family support, while others were hampered by factors at both micro and meso level. It was also possible that in different stages of a single life course, one pattern might succeed another, or young people might have followed shifting trajectories with regard to finding different kinds of employment (e.g., first stable job, current job, first temporary job). In the next step of our analysis, we focus on concrete patterns of agency - those adopted with regard to the young interviewees' first stable job.

\subsection{The Social Embeddedness of Patterns of Agency: A Cross-National Comparative Perspective}

In this section we seek to clarify some similarities and differences in the patterns of agency of young people regarding their first stable job in the different country-specific institutional environments and employment regimes of the seven EU countries studied.

Three main methodological problems necessitate caution when making comparisons between countries. First, the data were qualitative - between seven (NO) and $16(\mathrm{CZ})$ interviews with young people from the birth cohort 1990-95 were conducted in each country. Second, although the 
national samples had some common characteristics (e.g., the samples were gender balanced), they differed in relation to ethnic composition, place of residence and health status of the interviewees. Thus, the Bulgarian and Czech samples included some representatives of ethnic minorities (in the Czech sample 4 out of 16 interviewees were Roma; in Bulgaria 3 out of 14 were Roma; in Greece there were no interviewees from ethnic minority groups). In the Norwegian sample there were 3 interviewees with disabilities, whereas the German sample did not include any disabled people. The Norwegian sample included 3 people living in villages and small towns compared to 5 out of 10 in the German sample, while all young people lived in the capital city in the Greek sample. Third, we analysed the extended summaries of the interviews and not the full transcripts.

Table 6.1 presents the patterns of agency concerning the first stable job identified in the seven countries studied. The table shows the following:

- In this small and non-representative sample of cases, examples of successful (i.e., realized) agency dominated (59 out of 81 cases).

- Self-based successful agency accounted for 19 cases, while 40 successful agency cases were other-enabled.

- Amongst the other-enabled agency cases, support from friends was most frequent (18 cases), followed by support from family (12 cases).

- Strikingly few of the other-enabled cases of successful agency seemed to involve support from public agencies or NGOs (5 and 4 cases, respectively).

One would evidently need a larger and more representative sample to clarify the heuristic potential of the identified types and to investigate the possible mediating processes whereby young people experiencing early job insecurity converted their resources into new life prospects.

The table indicates the various types of positive agency spread unevenly across the countries studied, possibly reflecting contrasting institutional traits. As an indicator of such national traits, we use the notion of employment regimes. Such regimes involve different overall regulation of transitions from youth to adult employment. Hora et al. (Chapter 7 this volume) propose a distinction between five employment regimes that differ significantly with regard to four policy fields - education, active labour market policies, employment protection and unemployment protection. The countries under study here exemplify all five of the regimes: the inclusive/universal regime (NO), the employment-centred (dualistic) regime (GER), the liberal regime (UK), the sub-protective regime (GR) and the transitional/post-socialist regime (BG, CZ, PL).

Based on this classification, we make the following tentative observations 


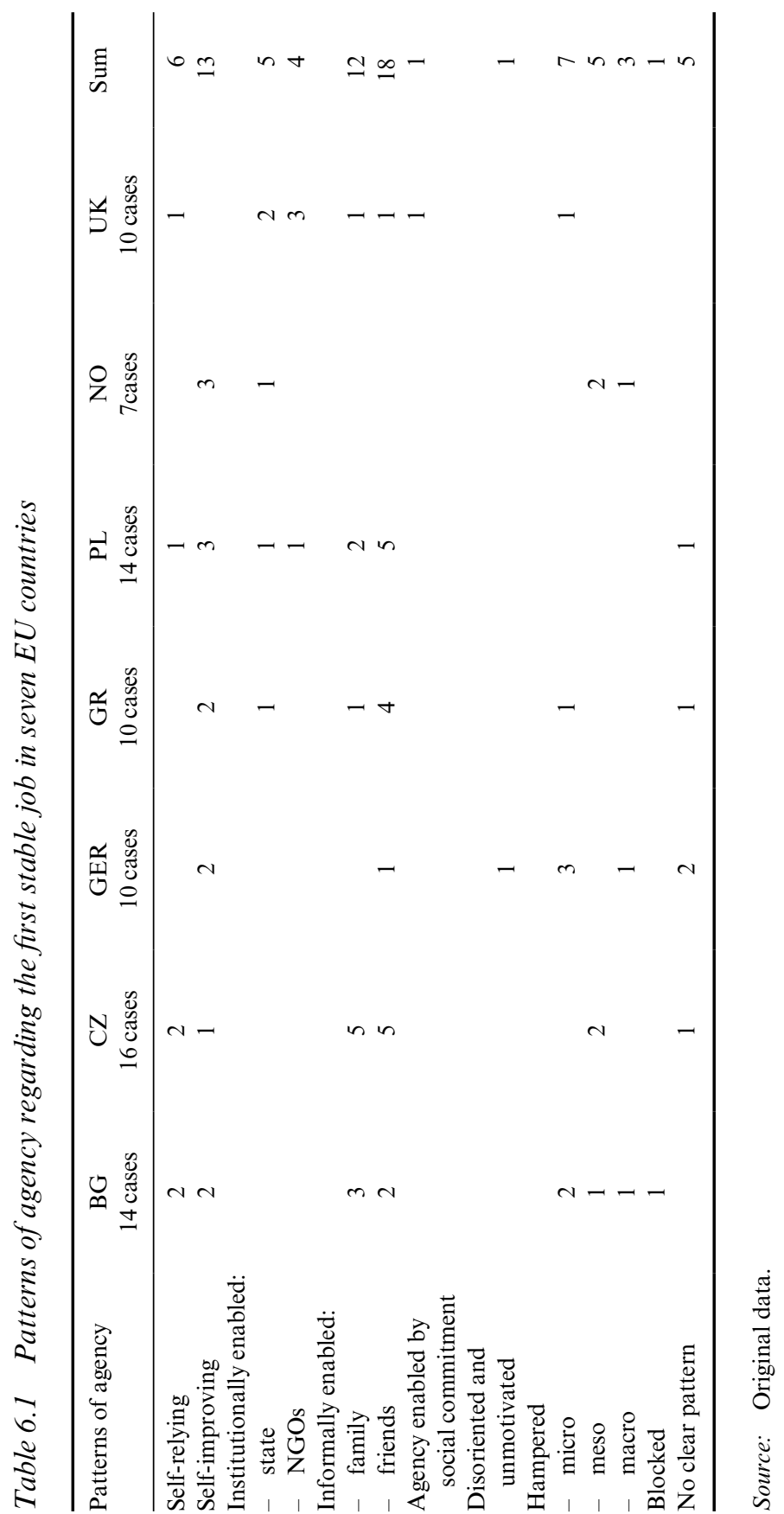


regarding the patterns of agency adopted by young people in finding their first stable job. Future research might test whether one finds similar patterns using large cross-national representative samples of young people who had experienced early job insecurity before the age of 25 :

- Successful agency enabled by family, relatives, social networks and friends seemed to have a more pronounced role in countries associated with sub-protective and transitional/post-socialist regimes than in the country associated with the liberal regime.

- Institutionally enabled agency appeared to have a less pronounced role in countries associated with transitional/post-socialist, subprotective and employment-centred regimes than in the country associated with the liberal regime.

- Self-enabled agency seemed to have approximately the same significance across the different regimes.

However, it should be emphasized that factors hindering young people's agency operate in country-specific ways. Thus, it is obvious that when unemployment hit Norwegian and UK youngsters, they put leaving the family home on hold for longer than originally planned; being adult in Norway and the United Kingdom was closely linked to forming a separate household, and moving away from home was a priority even when finances were tight. Moreover, the Norwegian interviewees generally did not speak of young children or other care responsibilities as a hindrance to their participation in the labour market.

\section{CONCLUSIONS}

This chapter contributes to the literature on agency and employment by adopting the capability approach in a number of ways. First, it demonstrates the heuristic potential of this approach for conceptualizing and understanding agency with regard to a situation of early job insecurity. Second, it identifies patterns not only of realized but also of unrealized agency. Third, although it is generally believed that it is possible to define agency only in relation to specific goals (e.g., Alkire, 2009), the chapter shows that one may also define agency in relation to the mediating processes through which young people seek to realize their goals. Fourth, it identifies agency achievements for people who have experienced early job insecurity. Fifth, the chapter further broadens the scope of applying the capability approach to the study of employment by using it as an analytical framework for clarifying the possibilities for agency and, through this, 
the potential for empowering a vulnerable group in Europe - young people experiencing early job insecurity.

Moreover, this chapter is in line with Hvinden and Halvorsen's recent study (2017), where the main argument is that the capability approach can enrich sociology's capacity to link human agency and structure in dynamic analyses of social inequality and marginality. Relying on the concepts of conversion processes and factors, the authors outline a model of agencystructure dynamics and the mechanisms through which the linkages between agency and structure are likely to emerge, reproduce or change. The model proposed in this chapter is a non-dynamic one and, as such, it is more in line with Robeyns's vision of the capability approach (2005). In contrast to the latter, however, our main emphasis is on agency in the specific case of young people who have experienced early job insecurity.

The analysis of the life-course interviews indicated that the patterns of (un)realized agency of young people in a situation of early job insecurity were embedded in national and institutional contexts and differed across countries with universal, employment-centred, liberal, sub-protective and transitional/post-socialist employment regimes. We agree with Bohle and Greskovits (2012) that the transitional countries are rather heterogeneous and experience different types of capitalism. In further research it would be worthwhile identifying additional types of employment regimes in order to capture the specificity of each of the post-communist countries.

Our analysis has also pointed to the unsettledness of young people, as well as to the various strategies they pursued to overcome early job insecurity. Early job insecurity turned out to be a serious predicament and even an obstruction - to the scope of agency of some young people. Although our focus has been on agency achievements, in many cases these were not sufficient to improve people's overall life situation and, more importantly, to enable them to acquire a feeling of well-being and realize valued and meaningful achievements in relation to employment. The analysis of the patterns of (un)realized agency has demonstrated that young people struggle to get out of such vicious circles on their own.

If young people improve their employment situation by finding a job, it may not be the job they have reason to value. From this perspective, if young people do not see good reasons to remain in a particular job, they may quit and continue to search for a more satisfactory one. Leßmann and Bonvin (2011: 97) highlight that the capability approach 'advocates participation and democratic procedures for arriving at a life one values'. Given this, an important aim for future research is to not only further examine the extent to which one finds the patterns of agency in different countries and cohorts but also to explore the conditions under which 
people are able to improve their working conditions and obtain the kind of job they have reason to value.

Finally, our study has identified an important policy challenge: How is it possible to empower people to interact and negotiate with different institutions in such a way that they can have greater success in converting available resources into new prospects and scope for real choice regarding employment? Our analysis has pointed to the need for adopting policies both at local and national level - that directly or indirectly enhance the capability sets of young people with respect to this very important dimension: being able to work, that is, being able to choose a personally valued professional life and to secure access to the labour market. In this way, young people would be empowered to function as active and fully participating citizens who are able to make autonomous decisions about their lives and to deal with the challenges they must face in the transition to adulthood.

\section{REFERENCES}

Alkire S (2009) Concepts and measures of agency. In: Basu K and Kanbur R (eds) Arguments for a Better World. Essays in Honor of Amartya Sen. Volume I: Ethics, Welfare, and Measurement. New York: Oxford University Press, pp.455-74.

Alkire S and Deneulin S (2009) The human development and capability approach. In: Deneulin S and Shahani L (eds) An Introduction to the Human Development and Capability Approach: Freedom and Agency. London, UK: Earthscan, pp. 22-48.

Bohle D and Greskovits B (2012) Capitalist Diversity on Europe's Periphery. Ithaca, NY: Cornell University Press.

Bonvin J-M and Farvaque N (2006) Promoting capability for work. The role of local actors. In: Deneulin S et al. (eds) Transforming Unjust Structures: The Capability Approach. Dordrecht: Springer, pp. 121-42.

Chung H and Van Oorschot W (2010) Employment insecurity of European individuals during the financial crisis. A multi-level approach. RECWOWE Working Paper on the Reconciliation of Work and Welfare in Europe no. 14. Edinburgh, UK: Dissemination and Dialogue Centre.

Crocker D and Robeyns I (2009) Capability and agency. In: Morris C (ed.) Amartya Sen. Cambridge, MA: Cambridge University Press, pp.60-90.

Egdell V and Graham H (2017) A capability approach to unemployed young people's voice and agency in the development and implementation of employment activation policies. Social Policy \& Administration 51(7): 1191-209. DOI: 10.1111/ spol.12262.

Engerman SL (2000) Max Weber as economist and economic historian. In: Turner $\mathrm{S}$ (ed.) The Cambridge Companion to Weber. Cambridge, MA: Cambridge University Press, pp. 256-71.

Eurofound (2014) Mapping Youth Transitions in Europe. Luxembourg: Publications Office of the European Union. 
Granovetter MS (1973) The strength of weak ties. American Journal of Sociology 78(6): 1360-80.

Granovetter MS (1985) Economic action and social structure: The problem of embeddedness. American Journal of Sociology 91(3): 481-510.

Hinchliffe G and Jolly A (2011) Graduate identity and employability. British Educational Research Journal 37(4): 563-84.

Hollywood E, Egdell V and McQuaid RW (2012) Addressing the issue of disadvantaged youth seeking work. Social Work \& Society 10(1): 1-18.

Hora O, Horáková M and Sirovátka T (2016) Institutional determinants of early job insecurity in nine European countries. NEGOTIATE Working Paper no. 3.4. https://negotiate-research.eu/files/2015/04/NEGOTIATE-working-paper-D3.4. pdf (accessed 16 April 2018).

Hvinden B and Halvorsen R (2017) Mediating agency and structure in sociology: What role for conversion factors? Critical Sociology. Epub ahead of print 9 January 2017. DOI: 10.1177/0896920516684541.

Karamessini M, Symeonaki M, Stamatopoulou G and Papazachariou A (2016) The careers of young people in Europe during the economic crisis: Identifying risk factors. NEGOTIATE Working Paper no. 3.2. https://negotiate-research.eu/files/2015/04/ NEGOTIATE-working-paper-no-D3.2-The-careers-of-young-people-in-Eurpaduring-the-economic-crisis.pdf (accessed 16 April 2018).

Leßmann O and Bonvin JM (2011) Job-satisfaction in the broader framework of the capability approach. Management Revue 22(1): 84-99.

McQuaid RW and Lindsay C (2005) The concept of employability. Urban Studies 42(2): 197-219.

Nussbaum M (2011) Creating Capabilities. The Human Development Approach. Cambridge, MA: The Belknap Press of Harvard University Press.

Olejniczak M (2012) Long-term unemployment and the capability approach: The case of the German labor market. Management Revue 23(2): 140-57.

Otto H-U (ed.) (2012) Transition from education to work - a question of justice. Jubilee edition. Social Work \& Society 10(1).

Otto H-U (ed.) (2015) Facing Trajectories from School to Work: Towards a Capability-Friendly Youth Policy in Europe. Dordrecht: Springer.

Robeyns I (2005) The capability approach: A theoretical survey. Journal of Human Development 6(1): 93-114.

Schneider K and Otto H-U (eds) (2009) From Employability Towards Capability. Luxembourg: Inter-Actions.

Sen A (1992) Inequalities Reexamined. Oxford, UK: Clarendon Press.

Sen A (1999) Development as Freedom. New York: Anchor Books.

Sen A (2009) The Idea of Justice. Cambridge, MA: The Belknap Press of Harvard University Press.

Tolgensbakk I, Vedeler JS and Hvinden B (2017) Youth unemployment and the consequences for life satisfaction and social trust in seven European countries. NEGOTIATE Working Paper no. 4.4. https://negotiate-research.eu/files /2015/04/NEGOTIATE-working-paper-no-D4.4-Youth-unemployment-and-the -consequences-for-life-satisfaction-and-trust.pdf (accessed 16 April 2018). 